\title{
Understanding the Intention to Use Commercial Bike-sharing Systems: An Integration of TAM and TPB
}

\author{
Ying $\mathrm{Yu}$ \\ College of Management \\ Shenzhen University \\ avayuying@126.com
}

\author{
Wenjie Yi \\ College of Management \\ Shenzhen University \\ 798527556@qq.com \\ Jia Liu \\ College of Management \\ Shenzhen University \\ 1191610412@qq.com
}

\author{
Yuanyue Feng \\ College of Management \\ Shenzhen University \\ yuanyuef@szu.edu.cn
}

\begin{abstract}
Commercial bike-sharing system is growing rapidly as a critical form of the sharing economy. Although past research has discussed the design and operation of commercial bike-sharing systems, there have been few studies examining the factors motivating the use of such systems. This study integrates the technology acceptance model (TAM) and the theory of planned behavior (TPB) to develop a holistic model to explain the intention to use commercial bike-sharing systems. The PLS-SEM results from a survey with 286 users reveal that the intention to use commercial bike-sharing systems is positively affected by perceived usefulness of the system, attitude toward bike-sharing and perceived behavioral control. Further, we find that attitude toward the bike-sharing is positively affected by perceived usefulness and perceived ease of use of the system. Beyond our expectation, subjective norm has no significant effect on the intention to use. Implications and directions for future research are also discussed.
\end{abstract}

Keywords: Commercial bike-sharing system; Intention to use; Technology acceptance model; Theory of planned behavior

\section{Introduction}

Rather than buying their favorite products or services, nowadays individuals tend to pay to temporarily access or share them, which is called the "sharing economy" [50]. PricewaterhouseCoopers has foreseen that five main sectors of sharing economy (i.e., collaborative finance, peer-to-peer accommodation, peer-to-peer transportation, ondemand household services, on-demand professional services) could generate a revenue of $\$ 335$ billion worldwide by 2025 [40]. It is noted that the surge of sharing economy is related to the pursuit of better value distribution of the supply chain [35], reduction of ecological impacts [57], technology advancement and finally, users' changing attitudes towards product ownership and their desire for social connections [12].

The sharing economy manifests in various forms, such as peer-to-peer (or P2P) rental market, accommodation sharing, and the vehicle sharing [40]. A prominent business model of the sharing economy, the commercial bike-sharing systems, has emerged in recent years as a popular way of public transportation [18]. For the society, commercial bike-sharing system meets the theme of sustainable development because of convenience, lower prices, and environmental protection [24, 29]. Consequently, many commercial bike-sharing systems are being established to satisfy the need. One example of commercial bike-sharing system is the CitiBikes, where there are more than 85,000 active users [57]. Another example is OFO, a large commercial bikesharing system in China. In OFO, there are on average 4.4 million active users per day [1].

Past research has noted that the adoption of the bike-sharing systems is crucial for the sustainability of the bike-sharing companies [39]. However, research has been primarily devoted to the design and operation of the commercial bike-sharing systems [15, 56]. There is little research examining individual's intention to use such systems. Without a clear understanding of the drivers for the system usage, companies are difficult to attract enough users and will lose in the market competition. 
Within the limited studies of the intention to use bike-sharing systems, some researchers borrowed the technology acceptance model (TAM) [25] to examine the effects of two system features (i.e., perceived usefulness (PU) and perceived ease of use (PEOU)) on users' adoption of bike-sharing systems [41, 49]. Apart from that, other scholars adopted the theory of planned behavior (TPB) [5] to examine the influence of users' attitude, subjective norms and perceived behavioral control on their intention to use bikesharing systems [46]. Past research has suggested that neither TAM nor TPB alone is able to provide consistently superior explanations or behavioral predication [16]. Although TAM has incorporated the two individual perceptions of system users, it has not accounted for the social influence in the users' adoption of new technology [19]. In the context of commercial bike-sharing systems, users might not only be motivated to use the system by their perceptions of the values and efforts associated with the use, but also being prompted by the desire for social connections with their peers [51]. Therefore, either TAM or TPB alone is unable to provide a complete picture for understanding the users' intention to use bike-sharing systems. In view of that, we purposefully integrate the TAM and TPB to explore and examine the antecedents of commercial bike-sharing system usage. We review prior literature to identify critical psychological factors and other context related literatures to theorize specific relationships among the model constructs.

\section{Literature review}

\subsection{Intention to use commercial bike-sharing system}

Commercial bike-sharing system is a new form of the sharing economy. It is a network of bicycles that are provided in subway stations, bus stops, campus, residential areas, commercial areas and public service areas [28]. According to [47], sharing bikes which do not belong to any individual will set aside whether use in a region for short-term communal. For the system users, commercial bike-sharing systems enable them to use a healthy, enjoyable, and relatively inexpensive door-to-door transport mode. More importantly, for the companies operating such systems, a large number of active users could generate supreme market revenues for them. Therefore, the frequent use of commercial bikesharing systems by a large amount of individuals is also crucial for the sustainability of such business model [39].
However, past literature on commercial bikesharing systems has largely dwelled on topics such as the design and operation of the commercial bikesharing systems $[15,56]$, as well as obstacles for the sustainability of the system, such as theft and sabotage [2], static rebalancing or repositioning problem $[15,56]$. There have been a limited number of studies trying to examine the motivators for the usage of such systems. For instance, [13] suggested that people who use the bike-sharing systems hold the beliefs that the sharing of bikes makes them more convenient to complete a short-distance travel inside the city, and help reduce traffic congestion as well as environmental pollution. Similarly, [9] suggested that convenience and the desire to avoid theft of private bikes are the key motivators for the system use. Moreover, [59] suggested that mechanisms such as adding stations and real-time bikes, improving bike maintenance and locking mechanisms, are needed to foster the use of bike-sharing service. As a synthesis, [31] argued that people are willing to use sharing bikes as there is no need to consider the responsibilities and costs associated with owning a private bike. However, research on the antecedents for the use of bike-sharing systems remains rare and scattered, partly because the bike-sharing system is still at its early development stage [64].

\subsection{Technology acceptance model (TAM) and theory of planned behavior (TPB)}

In the information systems discipline, the intention to use different kinds of information systems has been regarded as one of the most important research topics. Two theoretical lenses (i.e., TAM and TPB) rooted from the classical theory of reasoned action (TRA) [34] in the social psychology domain are frequently adopted to examine the intention to use different information systems.

The TAM model, first introduced by [25], tries to explain why individuals choose to use or not to use specific techniques by the "Perceived Usefulness" (PU) and "Perceived Ease of Use" (PEOU). Information systems scholars have relied on the TAM to understand individual's intention to use a variety of information systems, such as online games [44], online learning [3, 22], and social media [55]. Recently, the TAM has also been adopted to examine the intention to use bike-sharing systems. For example, [49] adopted an extended technology acceptance model (TAM) and found that customer's attitude toward the smart bike-sharing systems and perceived usefulness positively affect their use intention. [41] also discovered that perceived quality (perceived usefulness) and perceived convenience 
(perceived ease of use) foster the adoption of public bicycle sharing systems through perceived value.

Apart from TAM, the theory of planned behavior (TPB) suggests that individuals' technology adoption intention is jointly determined by their attitudes, subjective norms and perceived behavior control. Similar to the TAM, the TPB has also been adopted to study the intention to use a variety of information systems $[5,6,20]$. In the area of bike-sharing, TPB has been adopted as well. For instance, [61] based on TPB to indicate that cycling intentions are related to positive cycling experience, willingness to accept car restrictions, and negative attitudes towards cars. [46] applied the TPB and found that the tourists' intention to use sharing bikes for holiday cycling is positively affected by pro-cycling attitudes, interest in bicycle technology, cycling experience, and perceived cycling ease.

It is noted that TAM or TPB alone could not provide consistently superior behavior predictions [16]. And there have been some empirical supports for the better exploratory power with the integration of TAM and TPB [51]. Nevertheless, in the context of bike-sharing systems, there is yet to be a study which can integrate these two theoretical lenses into a holistic model. Hence, this study aims to fill this gap by integrating the TAM and TPB into a holistic research model to predict the intention to use the commercial bike-sharing systems.

\section{Research model and hypotheses development}

\subsection{Research model}

Drawing on the literature described above, we develop a model to explain individual's intention to use bike-sharing systems as shown in Fig. 1.

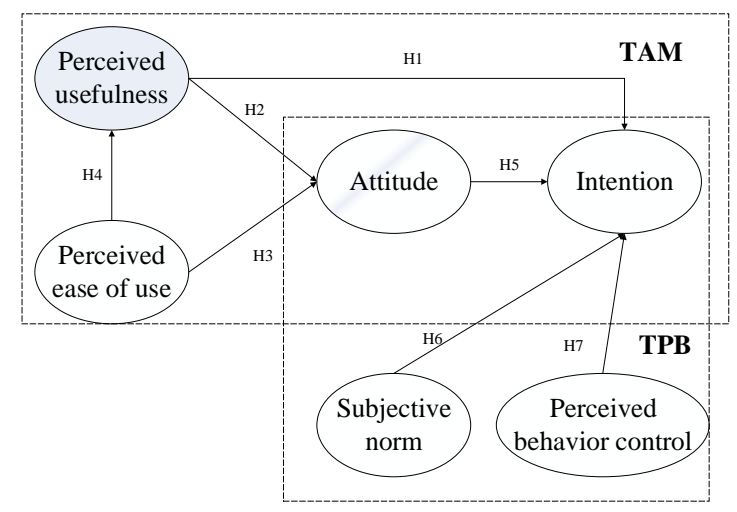

Figure 1. Research model

\subsection{Hypotheses development}

\subsubsection{Hypotheses about TAM.}

The first factor in TAM is perceived usefulness (PU), which is defined as the degree to which a person believes that the use of a particular system or technology will improve the performance of a particular activity $[10,25]$. It has been found in a study of bike-sharing system of a university campus that the bike-sharing program can help eliminate the need for additional parking, greenhouse emissions and traffic congestion, thereby helping reduce resource consumption and nurture a greener environment in campus [8]. Furthermore, cycling promotes a healthy lifestyle and improves the health of person. According to TAM and related literature, attitude and behavioral intention can be fostered by perceive usefulness [52]. When people feel that the commercial bike-sharing systems are useful and beneficial for them, they will develop a positive view toward the bike-sharing system, and be more willing to use the system. Hence, we postulate

H1: Perceived usefulness positively influences the intention to use bike-sharing system.

H2: Perceived usefulness positively influences the attitude toward the bike-sharing system.

Another important variable in TAM is the perceived ease of use (PEOU). Perceived ease of use is regarded as the extent to which a person believes that utilizing the technology could be effortless [25, 53]. In the context of bike-sharing systems, perceived ease of use is defined as the level at which users believe that the use of the bike-sharing system is free of effort. Prior works have indicated that perceived ease of use has positive effect on users' attitude [17, $43,45]$. Bike-sharing system just requires the users to have smart phones, and the unlocking and payment processes are very simple with just a few clicks. Hence, the less mental efforts needed by the system, the more likely users will have a positive attitude towards bike-sharing systems.

Besides, according to TAM, perceived ease of use also affects the perceived usefulness, which means that if user feels the system is easy to use, they will feel that the system is useful $[7,26,54]$. Hence, we hypothesize

H3: Perceived ease of use positively influences the attitude toward the bike-sharing system.

H4: Perceived ease of use positively influences the perceived usefulness of the bike-sharing system. 


\subsubsection{Hypotheses about TPB}

Attitude, referred to the individual's positive or negative feeling to the specific behavior, is a key antecedent in TPB that has been empirically shown to promote intention[48]. In this study, we define attitude as the user's preferences when using bikesharing system. Many studies show that there is a relationship between attitude and intention [32]. It's believed that if people have a positive attitude toward a specific situation, it will positively affect their intention, otherwise it will negatively affect their intention [51,58]. An empirical survey conducted by [46] suggested that tourists' intention for consumption of bike-sharing system is positively affected by their attitude towards it. When people hold positive feeling toward the adoption of bikesharing systems, they tend to more frequently use the systems. Hence, we hypothesize

H5: Attitude positively influences the intention to use bike- sharing system.

Subjective norm is defined as an individual's perception of social pressures towards the specific behavior where the pressures come from parents, friends, culture and public institutions [5]. Many studies have showed that subjective norms have a positive influence on a person's intention. [27] and [4] both suggested that the subjective norms are positive with the car use as people would be likely to think others expect them to travel by car. Furthermore, [42] thought that subjective norms only influenced the decision to commute by bikes in short distance. In the context of bike-sharing system, if using bike-sharing system is seen as socially desirable behavior, the individual is more likely to use it. That is to say, when people perceived a strong subjective norm of using bike-sharing system from others in the society, they will be more likely to use it to conform to the norm. Hence, we postulate

H6: Subjective norm positively influences the intention to use bike- sharing system.

Perceived behavioral control (PBC) refers to the degree of capability and control that a person perceives over performing a specific behavior [5]. It depends on the individual's beliefs about the power of both situational and internal factors to promote behavior [62]. When people think that they have more resources and opportunities and less expected obstructs, their perceived behavior control is stronger. As was proposed in [23], perceived behavioral control (PBC) was used to explain public transport users' intention to use routes with transfers. In an empirical study of the bike-sharing system, the result showed that students' intention to use the system is positively associated with their perceived behavioral control [63]. The more the control an individual feel about when using bike-sharing system, the more likely he or she will do so. Hence, we hypothesize

H7: Perceived behavioral control positively influences the intention to use bike-sharing system.

We also include gender, age, education level, and occupation in our model as control variables that might affect the intention to use commercial bikesharing systems.

\section{Research methodology}

We use the quantitative survey method to collect empirical data and test the above hypotheses. Both online and offline survey questionnaires were sent out. Details of the online and offline surveys, including the data collection and measurement of variables are provided below.

\subsection{Data collection and sample}

The online survey questionnaires are distributed by posting a microtask on the www.zbj.com, one of the largest crowdsourcing platforms in China. The microtask contained a link to the online questionnaire stored in a questionnaire service website called sojump (https://sojump.com) ${ }^{1}$. For the offline paperbased survey questionnaires, we randomly distributed them to the students in a university of Southern China and to the workers in a high-tech park near the university. When we distributed the questionnaires offline, we only informed the respondents about the purpose of this study. Both the online and offline respondents received $5 \mathrm{RMB}$ each for participation.

The survey questionnaires consisted of 3 sections. First, the participants were asked to answer some cognitive questions about the commercial bikesharing systems. Specially, we designed a question to ask whether the respondents have used any commercial bike-sharing systems before. Those respondents who haven't used any commercial bikesharing systems were excluded from the data analysis. In addition, we designed a multiple-choice question to ask the participants about the color of the OFO bike-sharing system, one of the largest commercial bike-sharing systems in China, and set the correct

${ }^{1}$ Sojump.com is one of the largest and well-known online questionnaire service website in China. 
answer in the first option. We set this question to check whether the participants did really know about the commercial bike-sharing systems. Those respondents who were unable to provide the correct answer were also excluded from data analysis. This question of OFO color was used to target more accurately on people who were familiar with the commercial bike-sharing systems and thus enhance the validity of our survey data. Next, this section is followed by questions that measure the theoretical constructs. The respondents were asked to rate their level of agreement with the statements regarding their perceptions of the commercial bike-sharing system using a Five-point Likert scale response format. It should be noted that we designed two reverse indicators to check whether the respondents have paid serious attention to the survey questions. The reverse items were used to identify and exclude those respondents who intentionally picked up the same Likert value throughout the survey and thus do not contribute appropriately to the survey. Specifically, when measuring the latent variable Perceived Ease of Use, the statements were set as "I think that using sharing bikes would be easy." "Learning how to use the sharing bikes is complicated. (R)". "For me, using the sharing bikes skillfully is very simple." "For me, the procedure of using the sharing bikes is very clear." "Overall, using the sharing bikes is complicated (R)." The second one and the last one were both reverse items. Then, we asked the same question regarding the color of the OFO sharing bikes again. But this time, we set the correct answer to the third option. This question was also used to check whether the respondents paid serious attention to the survey questions. Those respondents who answered these questions wrongly were excluded from data analysis. The last section was designed to collect respondents' demographic data, including their age, gender, educational level and their current jobs.

The online survey, which yielded 315 responses, and the offline survey, which yielded 40 responses, were received in one week. For the online/offline surveys, we deleted incomplete responses with missing data and responses that were finished within 65 seconds.And we also excluded respondents who haven't used the commercial bike-sharing systems and who failed to provide correct answers to the two questions regarding the color of OFO sharing bikes. This process results in a final sample size of 286 responses. Demographics of the respondents in the final sample are depicted in Table 1.

Table 1 Demographic information

\begin{tabular}{llll}
\hline Measure & Item & Frequency & Percent $(\%)$ \\
\hline
\end{tabular}

\begin{tabular}{llll}
\hline Gender & Male & 107 & 37.4 \\
& Female & 179 & 62.6 \\
\hline Age & $<18$ & 2 & 0.7 \\
& $18-24$ & 229 & 80.1 \\
& $25-31$ & 40 & 14 \\
& $32-38$ & 7 & 2.4 \\
& $>38$ & 8 & 2.8 \\
\hline Education & Below high & 1 & 0.3 \\
level & school & & \\
& High school & 9 & 3.1 \\
& /college & & \\
& University & 185 & 64.7 \\
& Master/PhD & 91 & 31.8 \\
\hline Occupation & Students & 205 & 71.7 \\
& Company staffs & 49 & 17.1 \\
& Government & 11 & 3.8 \\
& staffs & & \\
& Self-employed & 8 & 2.8 \\
& Others & 13 & 4.5 \\
\hline
\end{tabular}

\subsection{Measurement}

All measurement scales and items are adapted from existing literature as much as possible. In this paper, perceived usefulness and perceived ease of use were both measured with five items adapted from [25]. Subjective norm was measured by five items adapted from [5]. For the perceived behavioral control, we used five items adapted from [5, 21] to measure it. Besides, the measurements for the attitude toward the bike-sharing system consisted of 5 items adapted from [5, 21]. Lastly, for the dependent variable of intention, five items adapted from $[11,25]$ are used. All items used a five-point Likert-scale of 1 (strongly disagree) to 5 (strongly agree).

\section{Data analysis and results}

\subsection{The reliability and validity analyses}

We employed the SPSS statistical software 22.0 to conduct the reliability and validity analyses. According to Table 2, the Cronbach's Alpha (CA) of all the constructs are larger than the threshold of 0.7 , which shows high reliability of all the constructs.

After the reliability analysis, we conducted confirmatory factor analysis to test the validity of the constructs. The KMO value is 0.93 , which means that the survey items are suitable for factor analysis. As shown in Table 2, all the indicators loaded highly on their respective factor (larger than 0.5). Some items (PU1, PU2, PEOU1, PEOU2, SN1, SN4,SN5, PBC1, $\mathrm{PBC} 2$ ) were deleted due to their low loadings on respective constructs. We also assessed convergent validity by examining composite reliability (CR) and average extracted variance (AVE). The results in 
Table 2 demonstrate that each construct in the model has values of CR greater than 0.7 and a value of AVE greater than 0.5 . Thus, all constructs satisfied the criteria, demonstrating sufficient convergent validity.

\begin{tabular}{llllll}
$\begin{array}{l}\text { Table } 2 \\
\text { tests }\end{array}$ & Construct reliability and validity & \\
Construct & Item & $\begin{array}{l}\text { Factor } \\
\text { loading }\end{array}$ & CA & CR & AVE \\
\hline Perceived & PU3 & 0.73 & 0.93 & 0.96 & 0.88 \\
usefulness & PU4 & 0.74 & & & \\
& PU5 & 0.62 & & & \\
\hline Perceived & PEOU3 & 0.57 & 0.76 & 0.85 & 0.67 \\
ease of & PEOU4 & 0.53 & & & \\
use & PEOU5 & 0.87 & & & \\
\hline Attitude & ATT1 & 0.74 & 0.93 & 0.95 & 0.79 \\
& ATT2 & 0.81 & & & \\
& ATT3 & 0.77 & & & \\
& ATT4 & 0.82 & & & \\
\hline Subjective & SN2 & 0.75 & & & \\
norm & SN3 & 0.89 & 0.80 & 0.92 & 0.85 \\
\hline Perceived & PBC3 & 0.79 & 0.82 & 0.90 & 0.75 \\
behavior & PBC4 & 0.81 & & & \\
control & PBC5 & 0.84 & & & \\
\hline Intention & IU1 & 0.70 & 0.89 & 0.92 & 0.70 \\
to use & IU2 & 0.68 & & & \\
& IU3 & 0.77 & & & \\
& IU4 & 0.72 & & & \\
\hline & IU5 & 0.69 & & & \\
\hline
\end{tabular}

\subsection{Hypotheses testing}

After validating the measurement model as reported in the previous section, the path (structural) model was tested using PLS-SEM method with SmartPLS 2.0 software. The bootstrapping approach was used, with cases of 286 and samples of 5000.

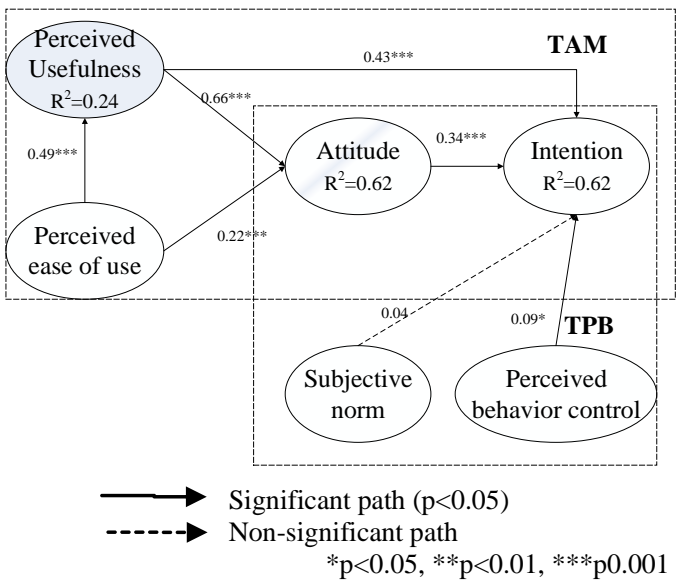

Figure 2. PLS-SEM Results
The path coefficients and their significance levels are shown in Fig 2. Most path coefficients had acceptable statistical significance level while the path from subjective norm to intention is shown to be nonsignificant.

Firstly, the effect of perceived usefulness on people's attitude towards commercial bike-sharing systems was 0.66 in the 0.001 level. This showed that $\mathrm{H} 2$ was fully supported. The p-values of the effects of perceived ease of use on perceived usefulness and the attitude are both less than 0.001. Hence, H3 and H4 were supported. When it comes to the effect of different variables on intention, as we can see in Figure 2, the effect of perceived usefulness on people's intention to use the bike-sharing system and the effect of attitude on the intention to use were both significant in the 0.001 level. Thus, H1 and H5 were fully supported. Perceived behavior control showed lower significance on the intention $(\mathrm{p}<0.05)$, but it also can be said that this effect was significant. That is to say, $\mathrm{H} 7$ was supported. Beyond our expectation, subjective norm showed non-significant effect on people's intention to use, which means that $\mathrm{H} 6$ was rejected. We would explain this unexpected result in the discussion section.

\subsection{Post-hoc regression analysis}

To justify our argument that the TAM in combination of TPB possess stronger explanatory power for the use of commercial bike-sharing systems, we conducted two stepwise regression analyses using SPSS 22.0 (see Table 3). The first stepwise regression analysis introduced the constructs of TAM into the model in the first step, which is followed by the constructs of TPB in the second step. The second stepwise regression analysis brought in the constructs of TPB into the model in the first step, then the constructs of TAM were added. The regression results showed that the changes of $\mathrm{R}$ square in both stepwise regression analyses were significant, indicating that our argument for the integration of TAM and TPB received support.

Table 3 Results of stepwise regressions

\begin{tabular}{llll}
\hline Step & $\begin{array}{l}\mathrm{R} \\
\text { square }\end{array}$ & $\begin{array}{l}\text { Change of } \\
\text { R square }\end{array}$ & $\begin{array}{l}\text { Significance of R } \\
\text { square change }\end{array}$ \\
\hline Step 1 of 1 & 0.59 & 0.03 & 0.00 \\
Step 2 of 1 & 0.62 & & \\
\hline Step 1 of 2 & 0.52 & 0.10 & 0.00 \\
Step 2 of 2 & 0.62 & & \\
\hline
\end{tabular}

\section{Discussion}


Our study presented and validated a multi-facet model for the usage of commercial bike-sharing systems. With empirical analysis, several lessons can be drawn.

The findings suggest that perceived usefulness is a significant factor in predicting the intention to use commercial bike-sharing systems. The results corroborate with previous research conducted on YouBike in Taiwan [19]. Since the costs are important factors in bike-sharing systems adoption [46], if users find the commercial bike-sharing systems are convenient and can save time for them, they are more likely to adopt and utilize the systems, and their attitudes towards the systems are more positive. Moreover, riding bikes fits well into a healthy and connected lifestyle. And the communities can see decreased $\mathrm{CO}_{2}$ emissions which increases the environmental quality of city [36]. All these various values could motivate the use of commercial bikesharing systems.

Additionally, results of this study suggest that perceived ease of use positively affect perceived usefulness, which is in line with that of [54] studies. Besides, our findings have also confirmed the argument that if users do perceive commercial bikesharing systems as being easy to use, they will develop a positive attitude toward the systems. This result also conforms to findings of prior works [17, 45]. Indeed, an easy-to-use interface could positively influence users' preferences whereas difficulties and obstructs encountered in the adoption process can lead to user's resistance.

As shown in Table 5, not all TPB components were significant predictors for the usage intention. Firstly, attitude positively influences the intention to use, which was also proved in previous studies [33]. Secondly, perceived behavior control is found to have a positive effect on the use intention, which is consistent with [37]. Finally, beyond our expectation, subjective norm has no significant effect on people's intention to use the commercial bike-sharing systems. The same conclusion also appeared in other contexts in previous studies [14]. The insignificant result might be due to the insufficient information regarding the commercial bike-sharing systems provided by the operating companies. Another reason might be that, sharing bikes has just appeared in recent years. Thus, respondents' family members, friends, and colleagues might know little about the commercial bike-sharing systems. Thus, they would not exert social pressures for the respondents to use the bike-sharing systems.

\section{Implications}

Findings of this study theoretically contribute to the current literature in several ways. First, this study enriches the literature of sharing economy by unraveling the antecedents (motivators) for the individual's intention to use a new business model of sharing economy, that is, commercial bike-sharing systems. Past literature has started to investigate the individual's intention to adopt different forms of sharing economy, such as the crowdsourcing platforms [66], the collaborative buying [38], and the car-sharing systems [30]. This study contributes to this line of research by exploring and examining the behavioral factors underlying the adoption of commercial bike-sharing systems.

Second, this study enriches the technology adoption literature by offering empirical supports for the better explanatory power of integrating the TAM with TPB in the context of commercial bike-sharing systems. Past research has indicated that the TPB is complementary to the TAM in enhancing the prediction of new technology adoption [51]. This study offers empirical supports for this theoretical argument by showing a greater explanatory power of the integration of TAM and TPB in predicting the use of commercial bike-sharing systems.

Third, this study further develops the TPB in the context of commercial bike-sharing systems by discovering the insignificant role played by subjective norm on use intention. It is found that at the infant development stage when the commercial bike-sharing systems are not widely received by the crowd, the subjective norms might not be a significant predictor for system usage. This study contributes to the TPB by identifying the potential role played by the development stages of new technology in its adoption, thereby paving the way for future research.

Practically, the findings of our study have important implications for commercial bike-sharing systems providers by offering valuable information about how to improve people's intention to use such a system. First, we found that perceived ease of use positively influences the attitude towards the systems and the use intention. Therefore, the bike-sharing operating companies should carefully design the usage procedures to make it as simple as possible, so as to reduce people's use disorders. For example, the operating companies should allow their users to access the systems and pay for the bill via existing social platforms like WeChat or Alipay, instead of requesting users to download and install an independent APP. Second, perceived usefulness is also found to foster the attitude and use intention. Therefore, the companies should repair the sharing bikes regularly to guarantee their performance. 
Besides, the operating companies should put more efforts on communicating the notion of usefulness of sharing bikes to the users. Apart from that, the findings showed that perceived behavior control also has a positive effect on people's use intention. Hence, the operating companies should enhance the users' autonomy in their use of the commercial bike-sharing systems. One thing the companies could do is to ensure that sufficient number of sharing bikes is reachable. So that when people need a bike for a short distance travel, they can find one quickly. In addition, the companies should delegate more rights for the users to decide on which bikes they want to use, and how they want to use it. The companies could also offer more types of bikes as well as more payment/pricing options to enhance the sense of behavioral control of the users.

\section{Limitation and future research}

This research has some limitations that we should acknowledge. First, most of our survey respondents are students in university. Although student sample might represent an appropriate subject for the examination of IT usage [65], future research should try to collect data from different types of individuals (e.g., workers) to further enhance the generalizability of the findings.

Second, our study was conducted in China, in which the intention to adopt commercial bike-sharing system might be as well affected by some other cultural or institutional factors, such as the facesaving culture or the green promotion policies by the government. Future research should try to take these aspects into account.

Finally, our study is based on cross-sectional data. With cross-sectional data, we can only take a snapshot of this model. A stricter test of our arguments, however, could be achieved by using a longitudinal study design. As the bike-sharing systems are still at the infancy stage, as technologies become more mature, there may be some different findings. Therefore, by using a longitudinal study in the future, we could investigate new results, thus providing more insight into the phenomenon of using commercial bike-sharing system.

\section{Acknowledgements}

The work described in this paper was financially supported by the National Natural Science Foundation of China grant (\#71702111, 71402098, 71502114, 71602122, 71701134), and the Natural Science Foundation of Guandong Province grant (\# 2014A030310314).

\section{References}

[1] "The Number of Users' of ofo Accounted for $60 \%$, Ranking First. The Total Number of Its Users Exceeds Mobike for More Than Six Months" http://www.sohu.com/a/166999034_571168 on 2017.08.24.

[2] China Daily. "Thefts and Sabotage a Problem for China's Bike-Sharing System." Retrieved from http://www.chinadaily.com.cn/china/2016/12/18/content_2 7700047.htm on 2017.06.15.

[3] Abdullah, F., and Ward, R. "Developing a General Extended Technology Acceptance Model for E-Learning (Getamel) by Analysing Commonly Used External Factors," Computers in Human Behavior (56), 2016, pp. 238-256.

[4] Abrahamse, W., Steg, L., Gifford, R., and Vlek, C. "Factors Influencing Car Use for Commuting and the Intention to Reduce It: A Question of Self-Interest or Morality?," Transportation Research Part F Traffic Psychology \& Behaviour (12:4), 2009, pp. 317-324.

[5] Ajzen, I. "The Theory of Planned Behavior," Organizational behavior and human decision processes (50:2), 1991, pp. 179-211.

[6] Ajzen, I. "Perceived Behavioral Control, Self-Efficacy, Locus of Control, and the Theory of Planned Behavior," Journal of Applied Social Psychology (32:4), 2002, pp. 665-683.

[7] Amin, H. "Factors Affecting the Intentions of Customers in Malaysia to Use Mobile Phone Credit Cards," Management Research News (31:7), 2008, pp. 493-503.

[8] Ashley, J. "Bike Sharing as Alternative Transportation at Bridgewater State University," Undergraduate Review (8:1), 2012, pp. 16-25.

[9] Bachand-Marleau, J., Lee, B. H. Y., and El-Geneidy, A. M. "Better Understanding of Factors Influencing Likelihood of Using Shared Bicycle Systems and Frequency of Use," Transportation Research Record Journal of the Transportation Research Board (2314:-1), 2012, pp. 66-71.

[10] Bandura, A. "Self-Efficacy Mechanism in Human Agency," American Psychologist (37:2), 1982, pp. 122-147.

[11] Bhattacherjee, A. "Understanding Information Systems Continuance: An Expectation-Confirmation Model," Mis Quarterly (25:3), 2001, pp. 351-370.

[12] Botsman, R., and Rogers, R. "What's Mine Is Yours: How Collaborative Consumption Is Changing the Way We Live," New York: Harper Collins, 2010.

[13] Castillo-Manzano, J. I., and Sánchez-Braza, A. "Can Anyone Hate the Bicycle? The Hunt for an Optimal Local Transportation Policy to Encourage Bicycle Usage," Environmental Politics (22:6), 2013, pp. 1010-1028. 
[14] Chau, P. Y. K., and Hu, J. H. "Investingating Healthcare Professionals' Decisions to Accept Telemedicine Technology: An Empirical Test of Competing Theories," Information \& Management (39:4), 2002, pp. 297-311.

[15] Chemla, D., Meunier, F., and Calvo, R. W. "Bike Sharing Systems: Solving the Static Rebalancing Problem," Discrete Optimization (10:2), 2013, pp. 120-146.

[16] Chen, C.-D., Fan, Y.-W., and Farn, C.-K. "Predicting Electronic Toll Collection Service Adoption: An Integration of the Technology Acceptance Model and the Theory of Planned Behavior," Transportation Research Part C: Emerging Technologies (15:5), 2007, pp. 300-311.

[17] Chen, C. F., and Chen, P. C. "Applying the Tam to Travelers' Usage Intentions of Gps Devices," Expert Systems with Applications An International Journal (38:5), 2011, pp. 6217-6221.

[18] Chen, S.-Y. "Using the Sustainable Modified Tam and Tpb to Analyze the Effects of Perceived Green Value on Loyalty to a Public Bike System," Transportation Research Part A: Policy and Practice (88), 2016, pp. 58-72.

[19] Chen, S. Y., and Lu, C. C. "A Model of Green Acceptance and Intentions to Use Bike-Sharing: Youbike Users in Taiwan," Networks \& Spatial Economics (16:4), 2015, pp. 1-22.

[20] Cheng, H.-H., and Huang, S.-W. "Exploring Antecedents and Consequence of Online Group-Buying Intention: An Extended Perspective on Theory of Planned Behavior," International Journal of Information Management (33:1), 2013, pp. 185-198.

[21] Cheng, T. C. E., Lam, D. Y. C., and Yeung, A. C. L. "Adoption of Internet Banking: An Empirical Study in Hong Kong," Decision Support Systems (42:3), 2006, pp. $1558-1572$

[22] Cheung, R., and Vogel, D. "Predicting User Acceptance of Collaborative Technologies: An Extension of the Technology Acceptance Model for E-Learning," Computers \& Education (63), 2013, pp. 160-175.

[23] Chowdhury, S., and Ceder, A. "A Psychological Investigation on Public-Transport Users' Intention to Use Routes with Transfers", International Journal of Transportation, (1:1) 2013, pp. 1-20.

[24] Cohen, B., and Kietzmann, J. "Ride On! Mobility Business Models for the Sharing Economy," Organization \& Environment (27:3), 2014, pp. 279-296.

[25] Davis, F. D. "Perceived Usefulness, Perceived Ease of Use, and User Acceptance of Information Technology," MIS Quarterly (13:3), 1989, pp. 319-340.

[26] Davis, F. D. "User Acceptance of Information Technology: System Characteristics, User Perceptions and Behavioral Impacts," International Journal of ManMachine Studies (38:3), 1993, pp. 475-487.

[27] Dijst, M. "Individual Needs, Opportunities and Travel Behaviour : A Multidisciplinary Perspective Based on
Psychology, Economics and Geography," Biochemistry (4:1), 2013, pp. 99-104.

[28] Easy, B. "Bicycle Share Feasibility Study, New Orleans," 2012.

[29] Eckhardt, G. M., and Bardhi, F. "The Sharing Economy Isn't About Sharing at All," Harvard business review (28:01), 2015.

[30] Efthymiou, D., Antoniou, C., and Waddell, P. "Factors Affecting the Adoption of Vehicle Sharing Systems by Young Drivers," Transport policy (29), 2013, pp. 64-73.

[31] Faghih-Imani, A., Eluru, N., El-Geneidy, A. M., Rabbat, M., and Haq, U. "How Land-Use and Urban Form Impact Bicycle Flows: Evidence from the Bicycle-Sharing System (Bixi) in Montreal," Journal of Transport Geography (41), 2014, pp. 306-314.

[32] Farahbod, F. "The Relationship between Trait Emotional Intelligence and Entrepreneurship Attitudes and Intentions," (5:3), 2013, pp. 79-85.

[33] Fen, Y. S., and Sabaruddin, N. A. "An Extended Model of Theory of Planned Behaviour in Predicting Exercise Intention," International Business Research (06:13), 2009, pp. 1685-1699.

[34] Fishbein, M., and Ajzen, I. "Belief, Attitude, Intention and Behaviour: An Introduction to Theory and Research," Philosophy \& Rhetoric (41:4), 1975, pp. 842-844.

[35] Gansky, L. The Mesh: Why the Future of Business Is Sharing. Penguin. 2010.

[36] Gardner, C., and Gaegauf, T. "The Impact of Bikesharing-White Paper on the Social, Environmental, and Economic Effects of Bikesharing," $A 2 B$ Bikeshare Website.

[37] Grønhøj, A., Bech-Larsen, T., Chan, K., and Tsang, L. "Using Theory of Planned Behavior to Predict Healthy Eating among Danish Adolescents," Health Education (113:1), 2012, pp. 4-17.

[38] Hamari, J., Sjöklint, M., and Ukkonen, A. "The Sharing Economy: Why People Participate in Collaborative Consumption," Journal of the Association for Information Science and Technology (67:9), 2016, pp. 2047-2059.

[39] Hampshire, R. C., and Marla, L. 2012. "An Analysis of Bike Sharing Usage: Explaining Trip Generation and Attraction from Observed Demand," 91st Annual meeting of the transportation research board, Washington, DC, pp. 12-2099.

[40] Hawksworth, J., and Vaughan, R. 2014. "The Sharing Economy-Sizing the Revenue Opportunity." www.pwc.co.uk.: PricewaterhouseCoopers, Available from: http://www.pwc.co.uk/issues/megatrends/collisions/sharing economy/the-sharingeconomy-sizing-therevenueopportunity. html .

[41] Hazen, B. T., Overstreet, R. E., and Wang, Y. "Predicting Public Bicycle Adoption Using the Technology 
Acceptance Model," Sustainability (7:11), 2015, pp. 1455814573.

[42] Heinen, E. A. "Bicycle Commuting," Delft University Press, Delft, 2011.

[43] Hsu, C. L., and Lin, C. C. "Acceptance of Blog Usage: The Roles of Technology Acceptance, Social Influence and Knowledge Sharing Motivation," Information \& Management (45:1), 2008, pp. 65-74.

[44] Hsu, C. L., and Lu, H. P. "Why Do People Play onLine Games? An Extended Tam with Social Influences and Flow Experience," Information \& Management (41:7), 2004, pp. 853-868.

[45] Jin, D., Chai, K. H., and Tan, K. C. "Organizational Adoption of New Service Development Tools," Managing Service Quality (22:22), 2012, pp. 233-259.

[46] Kaplan, S., Manca, F., Nielsen, T. A. S., and Prato, C. G. "Intentions to Use Bike-Sharing for Holiday Cycling: An Application of the Theory of Planned Behavior," Tourism Management (47), 2015, pp. 34-46.

[47] Kenney, G. "Bicycle Sharing Feasibility Study.," from University of Illinois at Urbana-Champaign, 2012, (Retrieved on September 14, 2017 at https://icap.sustainability.illinois.edu/files/project/107/Bicy cle $\% 20$ Sharing $\% 20$ Feasibility $\% 20$ Study $\% 20$ Final $\% 2011$ 30-12.pdf)

[48] Kusumawati, A. "Effects of Intention Mediation Towards Attitude, Subjective Norms and Perceived Behavioral Control on Taxpayers' Behavior," Journal of Research in Business and Management (2:10), 2015, pp. 26-32.

[49] Lai, W.-T. 2015. "Exploring Use Intention of a Smart Bike-Sharing System-Extending Technology Acceptance Model with Trust," In Zhang, Z., Shen, Z.M., Zhang, J., Zhang, R. (eds.) Liss 2014, pp. 1597-1603. Springer, Berlin (2014).

[50] Lamberton, C. P., and Rose, R. L. "When Is Ours Better Than Mine? A Framework for Understanding and Altering Participation in Commercial Sharing Systems," Journal of Marketing (76:4), 2012, pp. 109-125.

[51] Lee, M. C. "Factors Influencing the Adoption of Internet Banking: An Integration of Tam and Tpb with Perceived Risk and Perceived Benefit," Electronic Commerce Research \& Applications (8:3), 2009, pp. 130141.

[52] Lee, M. K. O., Cheung, C. M. K., and Chen, Z. "Acceptance of Internet-Based Learning Medium: The Role of Extrinsic and Intrinsic Motivation," Information \& Management (42:8), 2005, pp. 1095-1104.

[53] Lee, Y. H., Hsieh, Y. C., and Chen, Y. H. "An Investigation of Employees' Use of E-Learning Systems: Applying the Technology Acceptance Model," Behaviour \& Information Technology (32:2), 2013, pp. 173-189.

[54] Nysveen, H. "Intentions to Use Mobile Services: Antecedents and Cross-Service Comparisons," Journal of the Academy of Marketing Science (33:3), 2005, pp. 330346.

[55] Rauniar, R., Rawski, G., Yang, J., and Johnson, B. "Technology Acceptance Model (Tam) and Social Media Usage: An Empirical Study on Facebook," Journal of Enterprise Information Management (27:1), 2014, pp. 6-30.

[56] Raviv, T., Tzur, M., and Forma, I. A. "Static Repositioning in a Bike-Sharing System: Models and Solution Approaches," EURO Journal on Transportation and Logistics (2:3), 2013, pp. 187-229.

[57] Schor, J. B., and Fitzmaurice, C. J. " Collaborating and Connecting: The Emergence of the Sharing Economy," Handbook of research on sustainable consumption (410), 2015.

[58] Shah, S. S. H., Aziz, J., Jaffari, A. R., and Waris, S. "The Impact of Brands on Consumer Purchase Intentions," Asian Journal of Business Management (4:2), 2012, pp. 105-110.

[59] Shaheen, S., Zhang, H., Martin, E., and Guzman, S. "China's Hangzhou Public Bicycle: Understanding Early Adoption and Behavioral Response to Bikesharing," Transportation Research Record: Journal of the Transportation Research Board:2247), 2011, pp. 33-41.

[60] Sheeran, P., and Taylor, S. "Predicting Intentions to Use Condoms: A Meta-Analysis and Comparison of the Theories of Reasoned Action and Planned Behavior," Journal of Applied Social Psychology (29:8), 1999, pp. 1624-1675.

[61] Sigurdardottir, S. B., Kaplan, S., Møller, M., and Teasdale, T. W. "Understanding Adolescents' Intentions to Commute by Car or Bicycle as Adults," Transportation research part D: transport and environment (24), 2013, pp. 1-9.

[62] Suki, N. M., and Suki, N. M. "Students' Intention to Engage in Campus Environmental Activities and Green Initiatives: A Structural Equation Modelling Approach," International Journal of Social Ecology and Sustainable Development (IJSESD) (6:4), 2015, pp.15-33.

[63] Tafara, M., Sunarti, N., Kamarudin, S. S., and Osman, N.A. "2nd Regional Conference on Campus Sustainability," Regional Conference on Campus Sustainability. 2015.

[64] Te Pai, J., and Pai, S. Y. "User Behaviour Analysis of the Public Bike System in Taipei," Irspsd International (3:2), 2015, pp. 39-52.

[65] Ye, H. J., Feng, Y., and Choi, B. C. "Understanding Knowledge Contribution in Online Knowledge Communities: A Model of Community Support and Forum Leader Support," Electronic Commerce Research and Applications (14:1), 2015, pp. 34-45.

[66] Ye, H. J., and Kankanhalli, A. "Solvers' Participation in Crowdsourcing Platforms: Examining the Impacts of Trust, and Benefit and Cost Factors," The Journal of Strategic Information Systems (26:2), 2017, pp. 101-117. 